\title{
Residual effect of a micro-encapsulated formulation of organophosphates and piriproxifen on the mortality of deltamethrin resistant Triatoma infestans populations in rural houses of the Bolivian Chaco region
}

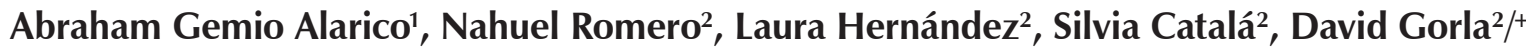 \\ 1Proyecto Chagas Inesfly Bolivia, Camiri, Santa Cruz de la Sierra, Bolivia \\ ${ }^{2}$ Centro Regional de Investigación Científica y Tecnológica de La Rioja, La Rioja, Argentina
}

The Bolivian Chaco is part of the endemic region of Chagas disease and an area where pyrethroid resistant Triatoma infestans (Hemiptera: Reduviidae) populations has been reported. The World Health Organization identified these resistant populations as an important focus for research. The objective of this study was to evaluate the residual effect of a micro-encapsulated formulation containing organophosphate active ingredients and a juvenile hormone analogue (Inesfly 5A IGR) on the mortality of T. infestans. Studies took place in rural houses of the Bolivian Chaco that were treated up to 34 months before and evaluated the susceptibility to pyrethroids of the offspring of field collected insects. Thirty houses were randomly selected within three communities to carry out wall bio-assays with $\mathrm{T}$. infestans nymphs. Mortality was recorded 24, 48 and $72 \mathrm{~h}$ after wall contact. Eggs laid by females collected in the area were used to obtain first-instar nymphs and carry out pyrethroid susceptibility tests. The wall bio-assays showed that the micro-encapsulated insecticide eliminates $\mathrm{T}$. infestans populations and produces detectable mortality of insects exposed to walls treated 34 months prior to the tests. The discriminant dose of deltamethrin $(0.01 \mathrm{mg} /$ $\mathrm{mL}$ ) showed $65 \%$ nymph survival, whereas at the highest tested dose $(1.0 \mathrm{mg} / \mathrm{mL}) 14 \%$ of the nymphs survived. These results show that Inesfly 5 A IGR is an appropriate tool for the elimination of intradomestic and peridomestic populations of $\mathrm{T}$. infestans resistant to pyrethroids.

Key words: Chagas disease - vector control - Triatominae - Triatoma infestans - insecticide resistance

Triatoma infestans (Hemiptera: Reduviidae) is the main vector of Trypanosoma cruzi (the etiologic agent of Chagas disease) in the Gran Chaco region of South America. Chagas disease is the most important parasitic disease in Latin America, the most frequent cause of myocardial pathologies and one of the most important neglected diseases identified by the World Health Organization (WHO). In the case of Bolivia, T. cruzi infection prevalence is among the highest in Latin America, ranging from $26-71 \%$ in children between 1-6 years of age and from $71-95.3 \%$ in the adult population (Jannin \& Salvatella 2006).

Due to the absence of a vaccine and the limited therapeutic response of currently available drugs, the options to reduce the burden of the disease depend on vector control using residual insecticides, house improvement and health education (Schofield 1994, WHO 2002). Since the 1980s, triatomine control has been primarily based on the use of pyrethroid residual insecticides that commonly have deltamethrin, lambdacyhalothrin and cyper-

Financial support: CONICET, Inesfly SL

+ Corresponding author: david.gorla08@gmail.com

Received 22 April 2010

Accepted 6 July 2010 methrin as active ingredients (Morel 1999). Pyrethroids are currently the main vector control tool because of their high efficacy, efficiency and residual activity, together with low risk of environmental contamination (Pinchin et al. 1980, Zerba et al. 1997, Gürtler et al. 2004, Cecere et al. 2006). After the remarkable success of the Southern Cone Initiative against Chagas disease vectors, which interrupted the vectorial transmission of T. cruzi in Uruguay, Chile, Brazil and several regions of Argentina and Paraguay, studies carried out during the last decade showed that vector control interventions in the Gran Chaco region had a lower performance compared with vector control interventions outside of the region (Schofield et al. 2006). The main difference is given by the presence of abundant populations of $T$. infestans living in the peridomestic structures of the Gran Chaco rural houses. In those habitats, the pyrethroid formulations showed lower efficacy, leaving residual populations that after 1-3 years reconstituted the original populations and eventually reinstalled the vectorial transmission of T. cruzi (Gürtler 2009). The recommended strategy for these places of repeating an insecticide application every six months is frequently not met for a number of reasons, with infrastructure, material and human resources availability and operational problems amongst the main problems.

Chagas, malaria and dengue are all endemic to the Chaco region of Bolivia. Due to this, the region has received vector control interventions based on dichlorodiphenyltrichloroethane (DDT), dieldrin and hexachloro- 
cyclohexane $(\mathrm{HCH})$ since 1959 , followed by pyrethroid treatments in the 1990s. More recently, the discovery of pyrethroid resistant $T$. infestans populations in the north of Argentina and southeastern Bolivia (Picollo et al. 2005, Catalá et al. 2007) led national control programs of both countries to use carbamate and organophosphate (OP) insecticides in several localities. The situation was identified as an important focus for research, because of its potential impact on the control of Chagas disease vectors (WHO 2005).

Since 1988, south and southwestern regions of the Bolivian Chaco have benefited from house improvement programs led by non-governmental organizations (NGO), oil companies and governmental agencies. Additionally, a series of field tests using a micro-encapsulated formulation of OP insecticides (developed by Inesfly, Spain) were carried out in the region of Camiri (Santa Cruz de la Sierra). The evaluation of several groups of houses by the departmental vector control programme showed a remarkable decrease in $T$. infestans prevalence among the treated communities (Dias \& Jemmio 2008). The success of these interventions was highly appreciated by the homeowners and other communities of Guaraní, in Santa Cruz and Tarija departments asked for the treatment of their new houses with the Inesfly paint.

The effect of the Inesfly 5A IGR micro-encapsulated formulation, together with the Inesfly $5 \mathrm{~A}$ IGR NG formulation based on pyrethroid active ingredients was experimentally studied under natural climatic conditions (Amelotti et al. 2009). Using different material supports, the authors reported $84 \%$ and $98 \%$ mortality of fourthinstar nymphs of $T$. infestans 18 months after application of the micro-encapsulated formulation.

The objectives of this study were (i) to evaluate the residual effect of Inesfly 5A IGR on the mortality of T. infestans in rural houses of the Bolivian Chaco and (ii) to evaluate the susceptibility to pyrethroids of the offspring of field collected $T$. infestans specimens. Although the treatment of houses was not planned for the present objective, the existing situation was used to design an observational study based on the time since the houses received the treatment with Inesfly 5A IGR.

\section{MATERIALS AND METHODS}

Study area - The study was carried out in October 2009 in houses of the Guaraní people in Ivamirapinta,

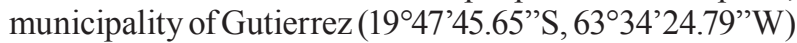
and Pampa Redonda, municipality of Lagunillas $\left(19^{\circ} 45^{\prime} 58.92^{\prime \prime}\right.$, $\left.63^{\circ} 33^{\prime} 41.26^{\prime \prime} \mathrm{W}\right)$ of the Santa Cruz de la Sierra and in Zapaterambia, municipality of Entre Ríos (21'11'49.75'S, 6347'21.69"W) of the Department of Tarija, towards the southeast of Bolivia (Fig. 1).

The area was sprayed with DDT and dieldrin by the National Malaria Eradication Service in the late 1950s and early 1960s. In the 1980s, the area was sprayed with $\mathrm{HCH}$ and during the 1990s with pyrethroids (lambdacyhalothrin WP $12.5 \%$ and deltamethrin SC 2.5 and 5\%). In 2002 alphacypermethrin SC 20\% was used. In areas with known resistance to pyrethroid, bendiocarb WP $80 \%$ was used during 2008 .
Ivamirapinta has 194 houses belonging to Guaraní people, some of them recently built with adobe walls and very good adobe plastering that were treated with Inesfly 5A IGR by professional technicians up to 30 days before this study (September 2009). A few houses were relatively old, with adobe walls of poorer quality than the newer ones, including many cracks in the adobe plastering. These old houses were treated with the micro-encapsulated formulation in the same way as the new houses. Peridomestic structures were infrequent in this locality. All pets (dogs, cats) and domestic animals for food production (goats, pigs, fowls) were in general kept on the common grounds surrounding the houses of the community. The only observed peridomestic structures were grain deposits ("troja") and a few chicken coops. House treatment activity in this locality was carried out during this study and a number of houses were not treated at the time.

Pampa Redonda has 36 houses occupied by a mix of Criollo and Guaraní ethnic groups. House plastering was improved and painted with Inesfly 5A IGR between December 2006-July 2007 (between 27-34 months before the present study was carried out) by community volunteers under professional technical supervision. The community keeps free range domestic animals (chickens, goats, pigs) without enclosures.

Zapaterambia has 40 relatively new houses, with good adobe walls and well finished adobe plastering. Zapaterambia is a Guaraní community close to an oil company that has a neighboring drilling field. The oil company, the local government and a group of NGOs developed a community based project to build new houses in Zapaterambia, including treatment with the Inesfly micro-encapsulated formulation applied by professional technicians between 3-4 months before the present study. No peridomestic structures for domestic animal enclosure were present.

The product - Inesfly $5 \mathrm{~A}$ IGR is a micro-encapsulated formulation containing OP active ingredients (chlorpyriphos $1.5 \%$ and diazinon $1.5 \%$ ) and an insect growth

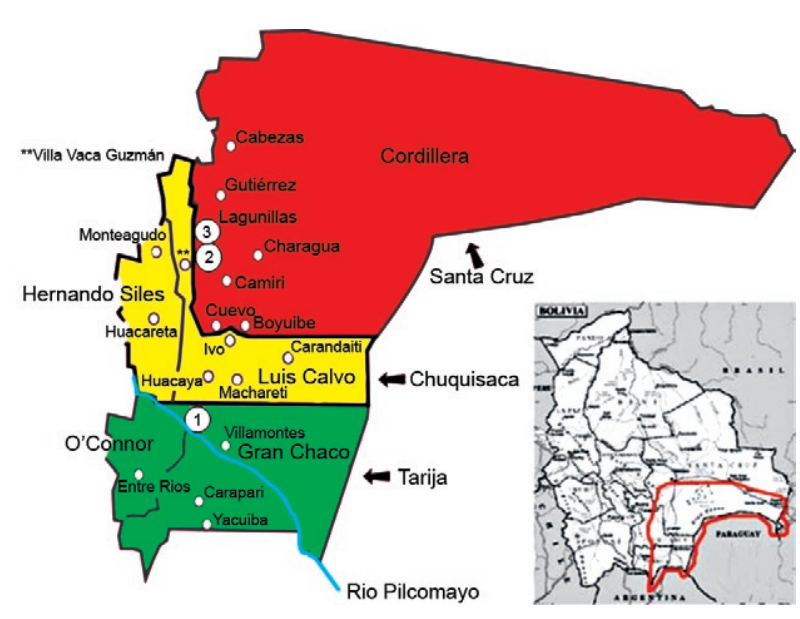

Fig. 1: map of the study area. Zapaterambia (1) (municipality of Entre Rios) is located in the province of Gran Chaco (Tarija Department). Ivamirapinta (2) (municipality of Gutierrez) and Pampa Redonda (3) (municipality of Lagunillas) are located in the province of Cordillera (Santa Cruz de la Sierra Department). 
regulator (pyriproxifen $0.063 \%$ ) that mimics the action of a juvenile hormone. The formulation has an aqueous base with the active ingredients encapsulated within micro-spheres of vinyl VeoVa polymer chains. The active ingredients are slowly and progressively liberated, a process that extends the insecticide residual activity of the formulation, as shown by Amelotti et al. (2009). More details about Inesfly 5A IGR, such as physical properties, advantages over conventional insecticides and insecticidal paints, are detailed in Herrero (2009).

Each house was painted with the micro-encapsulated formulation using four-gallons Jacto HD400 hand held sprayers, with JD12P cone nozzles (delivering 0.162 gallons per minute at $15-65 \mathrm{psi}$ ). An average of $1000 \mathrm{cc}$ of formulation was used to cover 10 square meters of internal walls and roofs, external walls and all peridomestic structures, where present. The product was applied as normal vinyl paint and presented no problems to obtain complete and smooth wall coverage. No particular treatment was used to treat wall or roof cracks (either adobe, wood logs or wooden sticks). After the intervention with the microencapsulated formulation, no additional vector control interventions were carried out in the three communities.

Wall bio-assays - This test was carried out to estimate $T$. infestans mortality produced by Inesfly 5 A IGR applied at different times. Insects used in the bio-assays were fourth and fifth $T$. infestans nymphs collected in Ivamirapinta during the four days prior to the wall bioassays. They were collected in peridomestic structures of Ivamirapinta houses that had not been treated with the insecticide formulation.

Ten houses were randomly selected within each of the three communities. One bedroom was randomly selected in each house to carry out the wall bio-assays. Two Petri dishes on different bedroom walls, containing 10 fourth and/or fifth-instar nymphs of $T$. infestans were attached to the walls, as described by Schofield (2001). The Petri dishes kept the insects in direct contact with the walls and remained attached between 12-16 h. After the contact period expired, Petri dishes were collected. Petri dishes with the same number of insects were allocated to the control group and were not attached to walls. All Petri dishes were kept at room temperature within an untreated house acting as a field laboratory. Nymph mortality was recorded 24, 48 and $72 \mathrm{~h}$ after wall contact.
Laboratory test of T. infestans susceptibility to pyrethroids - Eggs laid by T. infestans adult females collected in the peridomestic structures of Ivamirapinta were used to carry out pyrethroid susceptibility tests. The eggs were incubated in a rearing cabinet at a temperature of $28^{\circ} \pm 1^{\circ} \mathrm{C}$, relative humidity of $50 \pm 2 \%$ and a photoperiod of 12:12 h (L:D). T. infestans first-instar nymphs, 5-7 days of age, mean weight $1.3 \pm 0.2 \mathrm{mg}$ and unfed, were selected for pyrethroid susceptibility tests according to the WHO protocol (1994). The treatment consisted of topical application on the dorsal abdomen with $0.2 \mu \mathrm{L}$ of technical grade deltamethrin ${ }^{\circledR}$ (Bayer), diluted in acetone at different concentrations $(0.01,0.1,0.5$ and $1 \mathrm{mg} / \mathrm{mL}$ ), using a $10 \mu \mathrm{L}$ Hamilton syringe. Nymphs of the control group were treated with $0.2 \mu \mathrm{L}$ acetone alone. Three replicates, each with 10 first-instar nymphs, were assigned to each dose and the control groups. After $72 \mathrm{~h}$, the mortality rates of control and treated insects were recorded according to the WHO protocol (1994).

Data analysis - Kruskal Wallis ANOVA was used to compare the nymph mortality between communities. An analysis of mortality variability was carried out using the frequency distribution of mortality between communities.

Ethics - The study received authorization from the Santa Cruz de la Sierra Ministry of Health. House owners received a complete explanation about the objective of the study, procedures for the wall bio-assays and safety matters. House owners gave verbal individual consent to participate in the study.

\section{RESULTS}

Wall bio-assays - Wall bio-assays showed that the OP and juvenile hormone analogue microencapsulated insecticides produced detectable mortality of insects exposed to walls treated up to 34 months prior to the study. Mortality showed no significant difference (96.5 and $81 \%$ in Ivamirapinta and Zapaterambia, respectively) up to six months post treatment, but had decreased after 34 months to $22 \%$ (in Pampa Redonda). All insects in the control group were alive after $72 \mathrm{~h}$ (Table).

The nymph mortality variability was different among bio-assays performed in houses with different post-application times of the formulation. Nymph mortality in houses treated one month before the bio-assay (Ivamirapinta)

TABLE

Mortality of fourth and fifth-instar nymphs of Triatoma infestans exposed to house walls treated with the micro-encapsulated formulation Inesfly 5A IGR

\begin{tabular}{lcccc}
\hline Locality & $\begin{array}{c}\text { Time after insecticide } \\
\text { application (months) }\end{array}$ & $\begin{array}{c}\text { Replicates (houses) } \\
\mathrm{n}\end{array}$ & $\begin{array}{c}\text { Exposed T. infestans } \\
\mathrm{n}\end{array}$ & $\begin{array}{c}\text { T. infestans mortality } \\
\% \text { (CI 95) }\end{array}$ \\
\hline Ivamirapinta & $0-1$ & 10 & 200 & $96.5(92.9-98.6)$ \\
Zapaterambia & $2-6$ & 11 & 220 & $82.0(76.1-86.7)$ \\
Pampa Redonda & $27-34$ & 10 & 200 & $22.0(16.5-28.1)$ \\
\hline
\end{tabular}

exposure time varied between 12-16 h. CI 95: confidence interval for 95\% significance. 
was higher than $75 \%$ in $95 \%$ of the replicates, whereas $75 \%$ of the replicates in houses treated 34 months before the bio-assay (Pampa Redonda) showed $30 \%$ or less mortality. Nymph mortality in domiciles treated six months before the bio-assay (Zapaterambia) was high on average, although both replicates in one of the houses showed very low mortality (1 dead nymph out of 20).

Deltamethrin susceptibility tests - The topical application of deltamethrin in increasing doses showed that, even at the highest concentration, there were surviving nymphs after $72 \mathrm{~h}$. The discriminant dose of deltamethrin $(0.01 \mathrm{mg} / \mathrm{mL})$ and the highest tested dose $(1.0 \mathrm{mg} / \mathrm{mL})$ showed 65 and $86 \%$ nymph mortality, respectively (Fig. 2).

\section{DISCUSSION}

Results shown by this study indicate that the microencapsulated insecticide formulation Inesfly 5A IGR produces a detectable effect on the mortality of $T$. infestans, even in a locality where the compound had been applied 34 months before the present assay was performed. The measured residual effect is several times longer than the reported residual effect of suspension concentrate formulations under similar environmental conditions against $T$. infestans (Gürtler et al. 2004, Rojas de Arias et al. 2004). The wall bio-assays gave similar results to the experimental ones carried out on different substrate materials (wood, cement and adobe) reported by Amelotti et al. (2009) and confirmed previous reports (Dias \& Jemmio 2008). A similar micro-encapsulated formulation, using chlorpyriphos as active ingredient, produced a similar long lasting effect on Anopheles gambiae mortality when applied to experimental huts and bed nets (N'Guessan et al. 2010).

Houses in the studied communities are annually evaluated for infestation by $T$. infestans by field teams from the vector control programme of Santa Cruz de la Sierra and Tarija. Unpublished reports of these evalua-

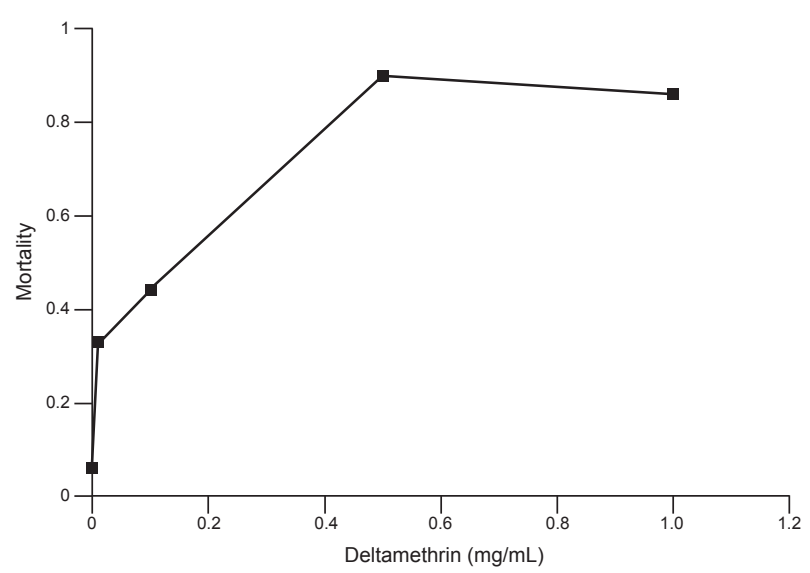

Fig. 2: survival of first instar nymphs of Triatoma infestans collected in Ivamirapinta (Santa Cruz de la Sierra, Bolivia), after $72 \mathrm{~h}$ of topical application of increasing concentrations of deltamethrin $[0.01 \mathrm{mg} / \mathrm{mL}$ is the susceptible discriminant doses according to Word Health Organization (1994)]. Each concentration is plotted with mean and standard deviation. tions indicate that none of the houses in the three studied communities were found infested after treatment in the intra or peridomestic structures.

The absence of house infestation by $T$. infestans is remarkable, especially in Pampa Redonda, where houses were treated 34 months prior to the present study. This case is remarkable because it is the first community that, although surrounded by nearby (untreated) localities with persistent $T$. infestans populations within houses, remains without detectable house infestation 34 months post treatment, according to the vector control programme of Santa Cruz de la Sierra. The wall bioassays showed that the micro-encapsulated formulation produced $22 \%$ mortality of exposed $T$. infestans in Pampa Redonda 34 months post treatment. This implies that during the previous period, the formulation probably killed all triatomines in Pampa Redonda, leaving no residual population to repopulate, as is often the case in many localities throughout Argentina, Bolivia and Paraguay (Gorla et al. 2009, Gürtler 2009). Considering these results, Pampa Redonda is free of triatomines unless a reintroduction occurs in the future.

The other remarkable aspect of this vector control intervention is that $T$. infestans populations of the Ivamirapinta region have shown high resistance to deltamethrin in the susceptibility tests carried out in this study. Resistance to pyrethroid was detected in northern Argentina in 2001 and several studies have reported pyrethroid resistance in $T$. infestans populations since then, especially in the Bolivian Chaco (Picollo et al. 2005, Catalá et al. 2007). Resistance to insecticides in triatomines is not completely understood. In several cases, the phenomenon seems nearer to insecticide tolerance than insecticide resistance, in other words, not strictly a consequence of the repetitive use of insecticides in a particular area. Pyrethroid resistance in triatomines shows a patchy spatial distribution, not necessarily associated with the intensity of pyrethroid use for triatomine control, as shown by Sonoda et al. (2009). Although there are no previous reports concerning $T$. infestans pyrethroid resistant populations in the studied region, this work indicates that it is effectively a deltamethrin resistant area. The long residual effect of the micro-encapsulated formulation against deltamethrin resistant $T$. infestans populations makes the studied product a useful candidate for the elimination of intradomestic and peridomestic populations of T. infestans in the area.

House owners of the studied communities showed satisfaction with the micro-encapsulated formulation, either because no triatomines, house flies, mosquitoes and spiders were present in the houses during a long period (more than 2 years according to some members of the communities) and/or because it gave the houses an aesthetic aspect that pleased the community (Dias \& Jemmio 2008).

\section{ACKNOWLEDGEMENTS}

To the Chagas Programme of Santa Cruz de la Sierra and to Jorge Llanos Espejo and Eddy Franz Espejo Lazarte, for the field support. 


\section{REFERENCES}

Amelotti I, Catalá SS, Gorla DE 2009. Experimental evaluation of insecticidal paints against Triatoma infestans (Hemiptera: Reduviidae), under natural climatic conditions. Parasit Vectors 2: 30.

Catalá S, Gorla DE, Juarez P, Picollo MI, Panzera F, Noireau F, Rojas Cortes M, Dujardin JP, Zerba E, Vassena C, Perez R, Calderón L, Abrahan L, Hernández ML, Cardozo R, Lopez E, Porcasi X, Moreno M, Schachter Broide J, Gürtler R, Lucero C, Ferrandis I, Calleros L, Ferreiro MJ, Cardozo L, Girotti J, Mijailovski S, Richter W, Kengne P, Perrineau MM, Cahuet A, Fontenille D, Herrera B, Gentile A, Gemio A, Alderete P, Diosque P, Acosta N, Alcaraz P, Llanos A, Uncos A 2007. Analytical appraisal, Southern Cone - biological and environmental causes of the spatial structuration in Triatoma infestans and the implications for vector control programmes. In Proceedings SSA/EC American Trypanosomiasis Update Workshop, Asunción, p. 13-18.

Cecere MC, Vázquez-Prokopec GM, Ceballos LA, Gurevitz JM, Zárate JE, Zaidenberg M, Kitron U, Gürtler RE 2006. Comparative trial of effectiveness of pyrethroid insecticides against peridomestic populations of Triatoma infestans in northwestern Argentina. J Med Entomol 43: 902-909.

Dias JC, Jemmio A 2008. Sobre uma pintura inseticida para controle de Triatoma infestans na Bolívia. Rev Soc Bras Med Trop 41: 79-81.

Gorla DE, Porcasi X, Hrellac H, Catalá SS 2009. Spatial stratification of house infestation by Triatoma infestans in La Rioja, Argentina. Am J Trop Med Hyg 80: 405-409.

Gürtler RE 2009. Sustainability of vector control strategies in the Gran Chaco region: current challenges and possible approaches. Mem Inst Oswaldo Cruz 104 (Suppl. I): 52-59.

Gürtler RE, Canale DM, Spillmann C, Stariolo R, Salomón OD, Blanco S, Segura EL 2004. Effectiveness of residual spraying of peridomestic ecotopes with deltamethrin and permethrin on Triatoma infestans in rural western Argentina: a district-wide randomized trial. Bull World Health Organ 82: 196-205.

Herrero PM 2009. Formación y funcionamiento de las microcápsulas poliméricas Inesfly: estudio de microscopía óptica y electrónica. Rev Tec Sater Ind Pint Tint 18: 1-13.

Jannin J, Salvatella R 2006. Estimación cuantitativa de la enfermedad de Chagas en las Américas/Quantitative estimation of Chagas disease in the Americas, Organización Panamericana de la Salud, OPS/HDM/CD/425-06, 28 pp.

Morel CM 1999. Chagas disease, from discovery to control - and beyond: history, myths and lessons to take home. Mem Inst Oswaldo Cruz 94 (Suppl. I): 3-16.
N'Guessan R, Boko P, Odjo A, Chabi J, Akogbeto M, Rowland M 2010. Control of pyrethroid and DDT-resistant Anopheles gambiae by application of indoor residual spraying or mosquito nets treated with a long-lasting organophosphate insecticide, chlorpyrifos-methyl. Malar J 9: 44.

Picollo MI, Vassena C, Santo Orihuela P, Barrios S, Zaidemberg M, Zerba E 2005. High resistance to pyrethroid insecticides associated with ineffective field treatments in Triatoma infestans (Hemiptera: Reduviidae) from Northern Argentina. J Med Entomol 42: 637-642.

Pinchin R, Oliveira Filho AM de, Fanara DM, Gilbert B 1980. Ensaio de campo para avaliação das possibilidades de uso da decametrina (OMS 1998) no combate a triatomíneos. Rev Bras Malariol Doencas Trop 32: 36-41.

Rojas de Arias A, Lehane MJ, Schofield CJ, Maldonado M 2004. Pyrethroid insecticide evaluation on different house structures in a Chagas disease endemic area of the Paraguayan Chaco. Mem Inst Oswaldo Cruz 99: 657-662.

Schofield CJ 1994. Triatominae. Biología y Control, Eurocommunica Publications, West Sussex, 80 pp.

Schofield CJ 2001. Field testing and evaluation of insecticides for indoor residual spraying against domestic vectors of Chagas disease, World Health Organization, Geneva, 62 pp.

Schofield CJ, Jannin J, Salvatella R 2006. The future of Chagas disease control. Trends Parasitol 22: 583-588.

Sonoda IV, Pessoa GC, Cortez MR, Dias JC, Romanha AJ, Diotaiuti L 2009. Susceptibility of Triatoma infestans to deltamethrin in Rio Grande do Sul, Brazil. Mem Inst Oswaldo Cruz 104: 668-670.

WHO - World Health Organization 1994. Protocolo de evaluación de efecto insecticida sobre triatominos. Acta Toxicol Argent 2: 29-32.

WHO - World Health Organization 2002. Control de la enfermedad de Chagas. Segundo informe del comité de expertos de la OMS, Serie de Informes Técnicos, WHO, Genebra, 117 pp.

WHO - World Health Organization 2005. Reporte del grupo de trabajo cientifico sobre la enfermedad de Chagas, TDR/SWG/09, WHO, Buenos Aires, 104 pp.

Zerba EN, Wallace G, Picollo MI, Casabé N, de Licastro S, Wood E, Hurvitz A, Andrés A 1997. Evaluación de la beta-cipermetrina para el control de Triatoma infestans. Rev Panam Salud Publica 1: 133-137. 